\title{
Internet of Things Based Low-Cost Real-Time Home Automation
}

\author{
Akanksha $^{1}$, Priti Mishra ${ }^{2}$ \\ Department of CSE, KNS Institute of Technology, Bangalore, India ${ }^{1,2}$
}

\begin{abstract}
Internet of Things (IoT) conceptualizes the idea of remotely connecting and monitoring real world objects (things) through the Internet [1]. When it comes to our house, this concept can be aptly incorporated to make it smarter, safer and automated. This IoT project focuses on building a smart wireless home security system which sends alerts to the owner by using Bluetooth in case of any trespass and raises an alarm optionally. Besides, the same can also be utilized for home automation by making use of the same set of sensors .This project presents an Internet of Things based real-time home automation and security system using Arduino UNO and HC-05 Bluetooth module which makes the system cost-effective and portable.
\end{abstract}

Keywords: Internets of Things (IoT), PIR Sensor, MQ2 Sensor

\section{INTRODUCTION}

Many people today prefer smart devices which can be controlled remotely by the Internet rather than the manual control to improve the standard of living. Internets of Things (IoT) is projected to provide dramatic improvements in smart home appliances. The Internet of Things (IoT) can be connecting various types of objects like smart phones, personal computer and tablets to the internet, which brings new fangled type of communication between things and things, and thinks and people [1].The Internets of Things technology is used to come in with innovative idea and large development space for smart homes to improve the living standards of life [2, 3].The growth of the Internet of Things will reform a number of sectors, like healthcare, automation, energy, transportation, etc. The cloud computing can be used in such case to implement the IoT infrastructure that augmented with sensors and actuators to monitor and control "things" from anywhere [4]. In this paper a low cost and user friendly remote controlled home automation system is presented using Arduino board, Bluetooth module, Smartphone, ultrasonic sensor and moisture sensor. A Smartphone application is used in the suggested system which allows the users to control up to 18 devices including home appliances and sensors using Bluetooth technology[5]. Nowadays, most of conventional home automation systems are designed for special purposes while proposed system is a general purpose home automation system. Which can easily be implementing existing home. The suggested system has more features than conventional home automation systems such as an ultrasonic sensor is used for water level detection and soil moisture sensor is use for automatic plant irrigation system. This paper also describes the hardware and software architecture of system, future work and scope. The proposed prototype of home automation system is implemented and tested on hardware and it gave the exact and expected results.

\section{HARDWARE SPECIFICATIONS}

\section{A. PIR Sensor}

The main component of a PIR sensor is the pyroelectric sensor which is present behind the plastic cap as can be seen in Fig 1.

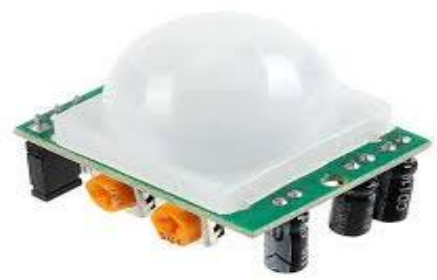

Fig 1. PIR sensor

An input voltage of 3-5 $\mathrm{V}$ is provided in pin 1 and digital output is obtained from pin 2.

The pyroelectric sensor is actually divided into two halves. When there is no motion, both halves receive the same amount of IR radiations from the surrounding. However, when a target crosses the sensor, the IR radiation level 
received at one half is more than the radiation at the other half. The PIR reacts to this change and makes the output HIGH. The range of detection goes up to 6meters, and it takes some time to stable itself according to the surrounding when it is powered ON.[6]

\section{B. MQ2 Sensor}

The MQ-2 is a flammable gas and smoke sensor detects the concentrations of combustible gas in the air and outputs its reading as an analog voltage. The sensor can measure concentrations of flammable gas of 300 to 10,000 Ppm. The MQ2 gas sensor is sensitive to LPG, i-butane, propane, methane, alcohol, Hydrogen and smoke. They are used in gas leakage detecting equipments in family and industry and in portable gas detector. Sensitive material of MQ-2 gas sensor is $\mathrm{SnO} 2$, which with lower conductivity in clean air. When the target combustible gas exist, The sensors conductivity is more higher along with the gas concentration rising. Please use simple electro-circuit, Convert change of conductivity to correspond output signal of gas concentration.MQ-2 gas sensor has high density to LPG, Propane and Hydrogen, also could be used to Methane and other combustible steam, it is with low cost and suitable for different application.

\section{Features:}

- $\quad$ Power supply needs: 5V

- Interface type: Analog

- $\quad$ Pin Definition: 1-Output 2-GND 3-VCC

- $\quad$ Wide detecting scope

- $\quad$ Fast response and High sensitivity

- $\quad$ Simple drive circuit

- $\quad$ Stable and long life

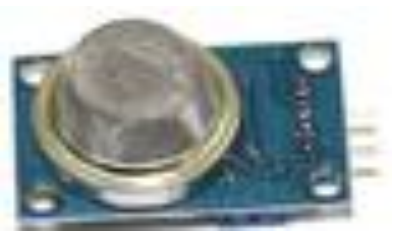

Fig 2. MQ2 Sensor

Resistance value of MQ-2 is difference to various kinds and various concentration gases. So, When using this components, sensitivity adjustment is very necessary. we recommend that you calibrate the detector for 1000ppm liquefied petroleum gas, or 1000ppm iso-butane concentration in air and use value of Load resistance that( RL) about $20 \mathrm{~K} \Omega(5 \mathrm{~K} \Omega$ to $47 \mathrm{~K} \Omega)$. When accurately measuring, the proper alarm point for the gas detector should be determined after considering the temperature and humidity influence.

\section{Light Sensor}

There are different types of light sensors available such as photo resistors, photodiodes, photovoltaic cells, phototubes, photomultiplier tubes, phototransistors, charge coupled devices, and so on. But, LDR (Light Dependent Resistor or photo-resistor) is used as a light sensor in this light sensor circuit. These LDR sensors are passive and doesn't produce any electrical energy.

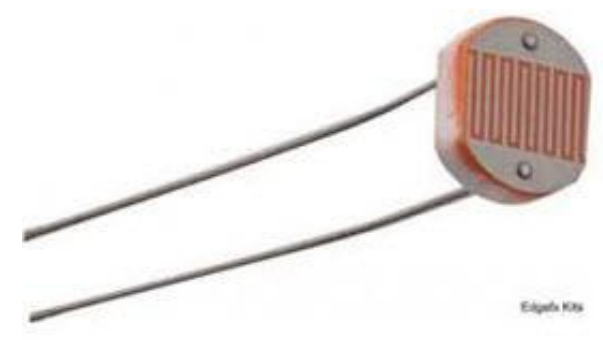

Fig 3.LDR Light Sensor

But, the resistance of the LDR changes with the change in the (light illuminated on the LDR) daylight intensity. LDR sensor is rugged in nature, hence can be used even in dirty and rough external environments. Hence, LDR is preferable compared to other light sensors as it can be used even in the outdoor lighting of homes and in automatic street lights as well. Light Dependent Resistor is a variable resistor that is controlled by light intensity. LDRs are made of high resistance semiconductor material Cadmium Sulphide that exhibits photoconductivity.

During night time (when the light illuminated on LDR decreases), the LDR exhibits a very high resistance of around a few M $\Omega$ (Mega Ohms). During daytime, (when the light is illuminated on LDR), resistance of LDR decreases to 
around a few $100 \Omega$ (hundred Ohms). Hence, the resistance of LDR is inversely proportional to the light illuminated on LDR.

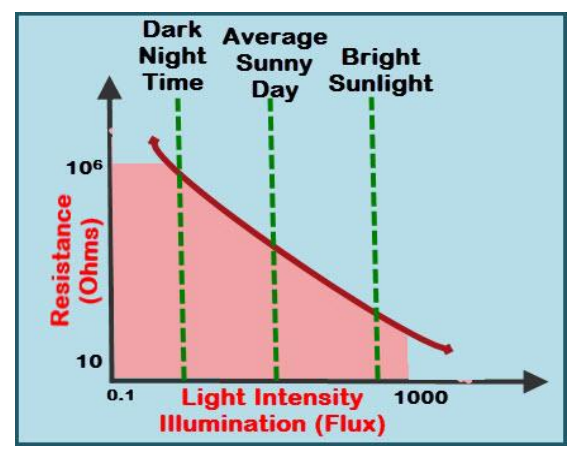

Fig 4.Light Intensity vs LDR Resistance

As shown in the above figure, the LDR consists of two terminals similar to a general resistor and a wave-shaped design on its top surface. The graph shown above represents the inverse proportionality of the LDR with the light intensity.The major drawback of the LDR is that, it is sensitive to light illuminated on it irrespective of the nature of light (natural daylight or even artificial light).

Darlington Pair: The back-to-back connection of two transistors is called as a Darlington pair, this Darlington pair transistor connection is used in this light sensor circuit.

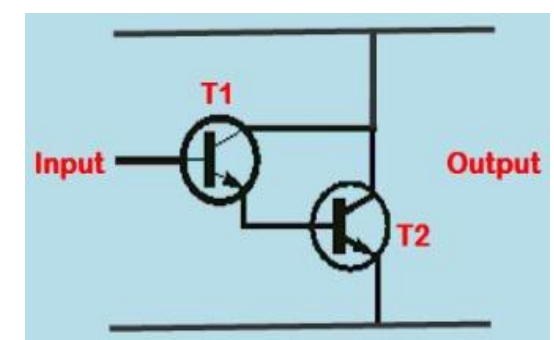

Fig 5. Circuit Diagram Of LDR

This Darlington pair transistor is also considered as a single transistor that has very high current gain compared to the general transistor gain. The product of input current and gain of the transistor gives the input given to the load through the Darlington pair. We know that, if the base voltage must be greater than $0.7 \mathrm{v}$, then the transistor switches on - but, in case of Darlington pair, the base voltage must be $1.4 \mathrm{v}$ as the two transistors are required to be switched on.

\section{DHT11 Sensor}

DHT11 digital temperature and humidity sensor is a composite Sensor contains a calibrated digital signal output of the temperature and humidity. Application of a dedicated digital modules collection technology and the temperature and humidity sensing technology, to ensure that the product has high reliability and excellent long-term stability. The sensor includes a resistive sense of wet components and an NTC temperature measurement devices, and connected with a high-performance 8-bit microcontroller.

Applications: HVAC, dehumidifier, testing and inspection equipment, consumer goods, automotive, automatic control, data loggers, weather stations, home appliances, humidity regulator, medical and other humidity measurement and control.

Features: Low cost, long-term stability, relative humidity and temperature measurement, excellent quality, fast response, strong anti-interference ability, long distance signal transmission, digital signal output, and precise calibration.

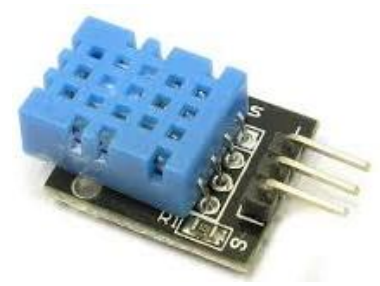

Fig 6. DHT11 Sensor 
Electrical Characteristics

Power supply: DC $3.5 \sim 5.5 \mathrm{~V}$

Supply Current: measurement $0.3 \mathrm{~mA}$ standby $60 \mu$

A Sampling period: more than 2 seconds

\section{Pin Description}

1, the VDD power supply $3.5 \sim 5.5 \mathrm{~V}$ DC

2 , DATA serial data, a single bus

3 , NC, empty pin

4, GND ground, the negative power.

\section{E. Arduino UNO}

The Arduino UNO is a widely used open-source microcontroller board based on the ATmega328P microcontroller and developed by Arduino.cc. The board is equipped with sets of digital and analog input/output (I/O) pins that may be interfaced to various expansion boards (shields) and other circuits. [7] The board features 14 Digital pins and 6 Analog pins. It is programmable with the ArduinoIDE(Integrated Development Environment) via a type B USB cable. It can be powered by a USB cable or by an external 9 volt battery, though it accepts voltages between 7 and 20 volts. It is also similar to the Arduino Nano and Leonardo. The hardware reference design is distributed under a Creative Commons Attribution Share-Alike 2.5 license and is available on the Arduino website. Layout and production files for some versions of the hardware are also available. "Uno" means one in Italian and was chosen to mark the release of Arduino Software (IDE) 1.0. The Uno board and version 1.0 of Arduino Software (IDE) were the reference versions of Arduino, now evolved to newer releases. The Uno board is the first in a series of USB Arduino boards, and the reference model for the Arduino platform. The ATmega328 on the Arduino Uno comes preprogrammed with a boot loader that allows to upload new code to it without the use of an external hardware programmer. It communicates using the original STK500 protocol. The Uno also differs from all preceding boards in that it does not use the FTDI USB-toserial driver chip. Instead, it features the Atmega16U2 (Atmega8U2 up to version R2) programmed as a USB-to-serial converter. The Arduino UNO is generally considered the most user-friendly and popular board, with boards being sold worldwide for less than $5 \$$.

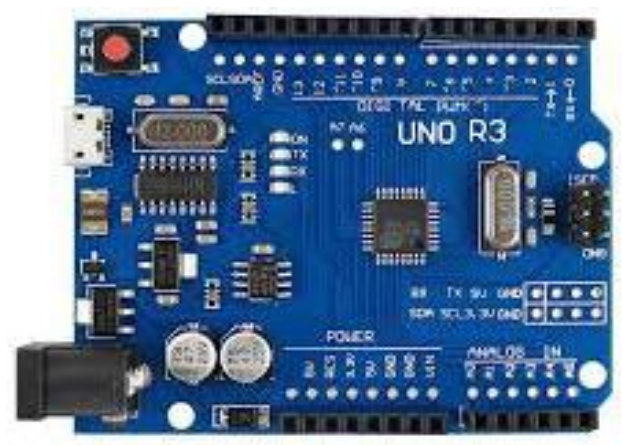

Fig 7.Arduino UNO

\section{RELATED WORK}

Efficiency and security are of utmost importance to us. An efficient and secure system if implemented should have the following important ideas in place. Firstly, the system should be made aware of to the perpetrator.

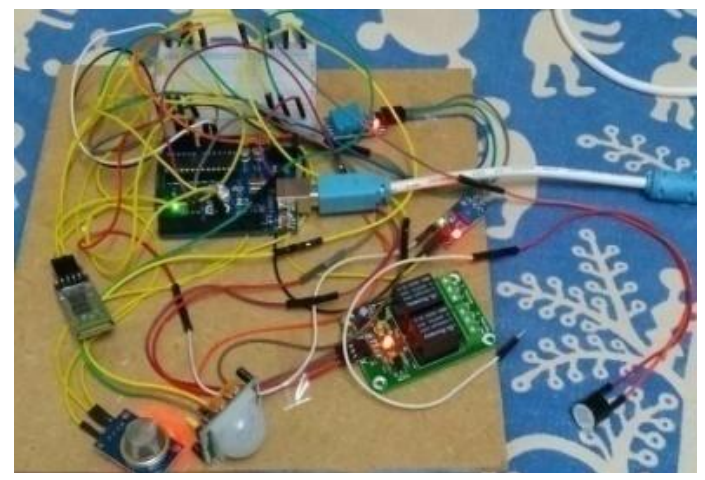

Fig 8. Circuit Of The Working Model 


\section{IJARCCE}

\section{International Journal of Advanced Research in Computer and Communication Engineering}

Vol. 7, Issue 12, December 2018

The home owner should then be alerted in order that he takes some action. Finally, there ought to be a recording device to trace what's happening, which could later be will not to assist the police to search out the stolen/misplaced things [1]. The alert mechanism will be incorporated employing a cellular device like a portable. The design consists of Android phone with the home automation application, Arduino Ardutooth APK. In the proposed system we provide an open source app that can be easily accessed by the user without have to paying for it and is simple to use to retrieve the data. The system will be transferring the real time data continuously to the mobile application at the terminal side. This helps the user in monitoring the data whenever the user wants, by pairing it up with the Bluetooth module.

- $\quad$ As the system is powered up all the components start working, as we enter a command $(\mathrm{Ctrl}+\mathrm{Shift+M})$ the output screen starts displaying the obtained result on the screen.

- $\quad$ The temperature and humidity values keep varying as the variations in temperature and humidity keep happening.

- $\quad$ The smoke sensor senses the type of gas and the gas density in the home, also it detects the gas leakage in the home. As the sensing value goes higher than the normal value, a buzzer creates the alarm for the user to take the necessary actions.

- LDR sensor helps in detecting the intensity of light. Since $I \propto 1 / \mathrm{V}$ the density of light drops suddenly as the voltage increases. High voltage may also burn the home appliances. To prevent the alarm is created again for the user.

The LED starts to blink and the relay trips.

- The motion of a human is detected when the value of PIR sensor goes upto 1,else the motion is not detected.

- The obtained data is then been transferred to the connected user,the user has to pair up with Bluetooth device(HC-05) and the real time data will continuously be sent to the user at the terminal end.

\section{RESULTS}

The results are obtained on the Serial monitor. Fig 9shows the serial monitor, which shows the simulation results of the sensors when entered a command $(\mathrm{Ctrl}+\mathrm{Shift}+\mathrm{M})$, also the serial plotter is used for plotting graphs. The Fig 10 is showing the plotted graph of the sensor values. Fig 11 shows the terminal end of the app on which the user receives the data.

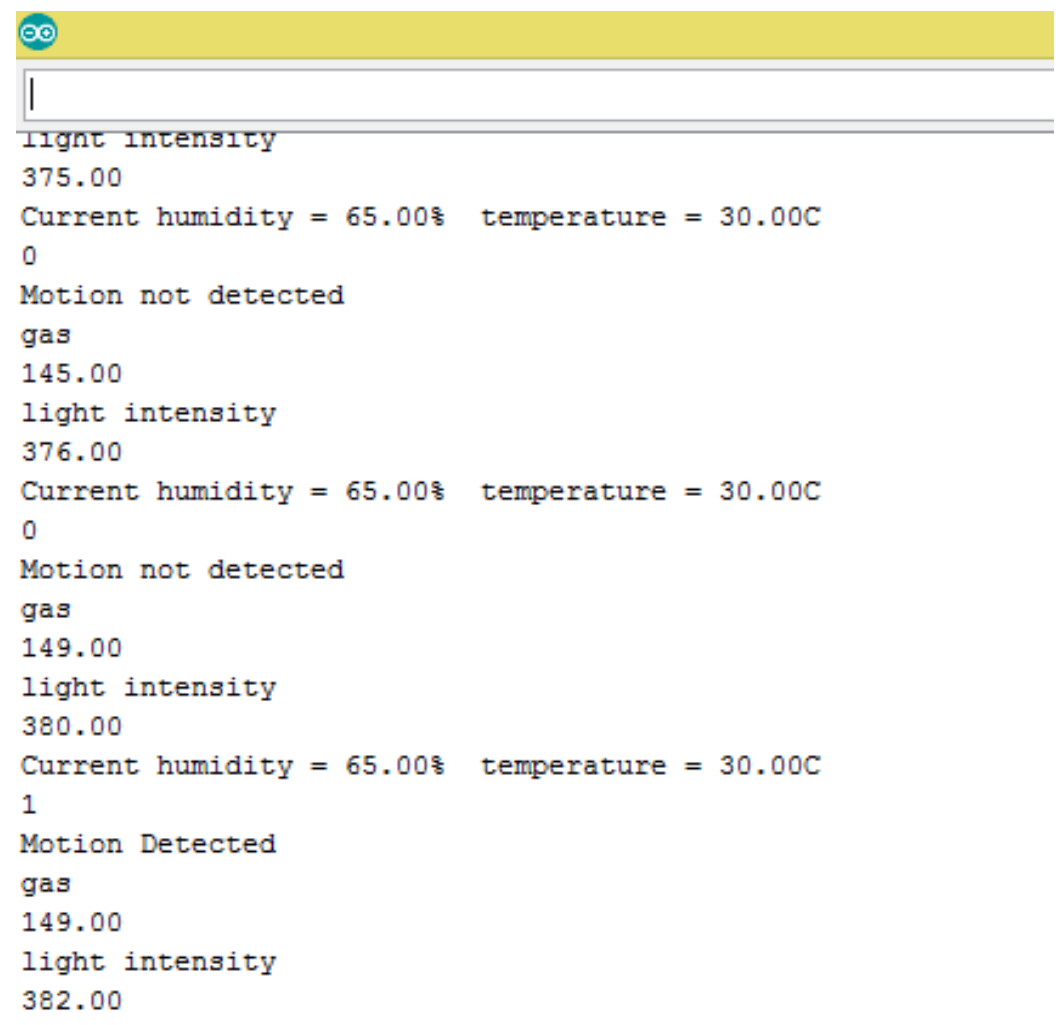

Fig 9. Output Screen Of the Arduino Sketch 
Vol. 7, Issue 12, December 2018
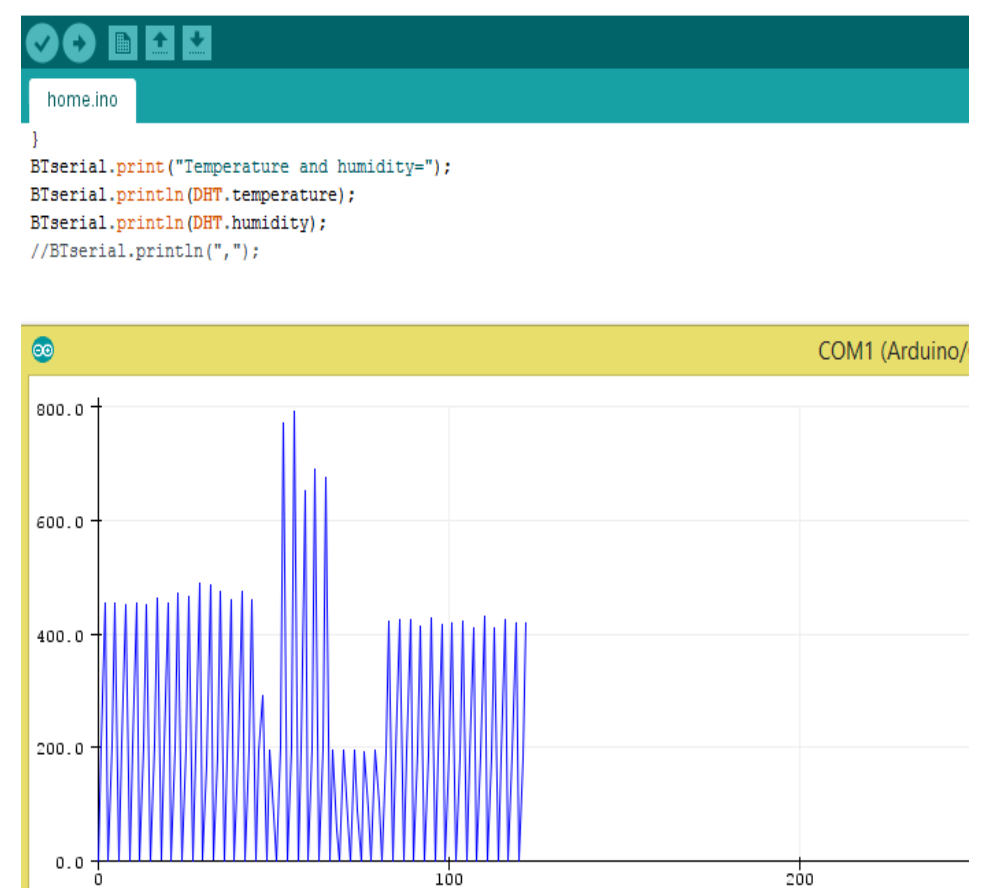

Fig 10.Serial Plotter
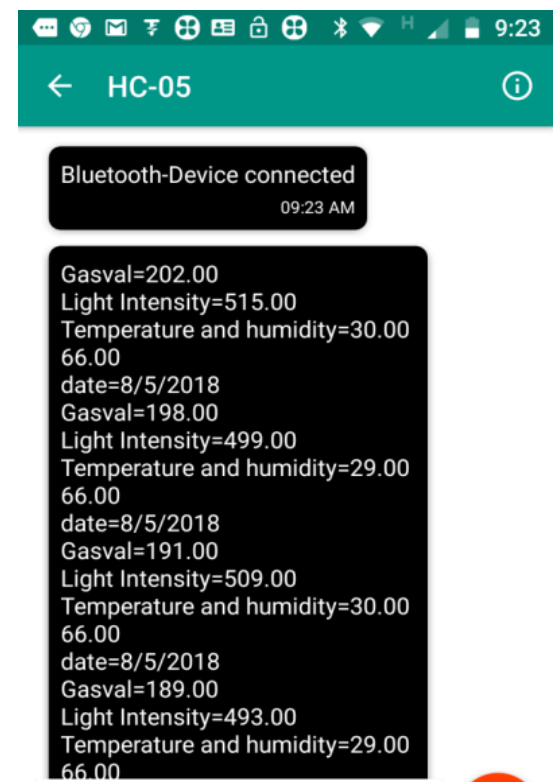

66.00

Type your message

\section{$\triangleleft$}

Fig 11. Obtained data on the terminal screen(mobile app).

\section{CONCLUSION}

In this present work, a novel architecture for flexible home automation and security system using Internet of Things (IoT) has been implemented. The basic idea of "Internet of Things based low-cost real-time home automation The proposed system can be expanded by adding RFID card system to provide a total security to the house, which will basically have a master card and a normal user card.Also we can add a moisture sensor to our proposed system ,which will help the user in determining the moisture present in the garden's soil so that the user doesn't have to check the moisture in plants everyday and can take necessary actions if the moisture value is detected below the required amount of moisture. We can add a D6T sensor to detect the human presence for the accurate reading , on basis of which the home appliances will automatically get turned on/off. 


\section{ACKNOWLEDGEMENT}

This work was supported by KNS Institute Of Technology under the guidance of Associate Professor Dr .Priti Mishra.

\section{REFERENCES}

[1]. PoojaN.Pawar, ShrutiRamachandran, Nisha Singh, Varsha V.Wagh,"A HOME AUTOMATION SYSTEM USING INTERNET OF THINGS”, IJIRCCE, Vol. 4, Issue 4, April 2016.

[2]. Jaeseok Yun, Min-Hwan Song, "DETECTING DIRECTION OF MOVEMENTUSING PYROELECTRIC INFRARED SENSORS" IEEE Sensors Journal, vol.15, no.5 pp.1482-1489, May 2014.

[3]. Y. Zhou, X. Yang, L Wang, "A WIRELESS DESIGN OF LOW-COST IRRIGATIONSYSTEM USING ZIGBEE TECHNOLOGY", IEEE 2009 International Conference on Networks Security Wireless Communications andTrusted Computing, vol. 1, pp. 572-575, 2009.

[4]. D.-M. Han, J.-H.Lim, "DESIGN AND IMPLEMENTATION OF SMART HOMEENERGY MANAGEMENT SYSTEM BASED ON ZIGBEE", IEEE Transaction on Consumer Electronics, vol. 56, no. 3, pp. 1417-1425, Aug. 2010.

[5]. J. Lagorse, D. Paire and A. Miraoui, "A MULTI-AGENT SYSTEM FOR ENERGYMANAGEMENT OF DISTRIBUTEDPOWER SOURCES," Renew. Energy, vol. 35, no.1, pp. 174-182, January 2010.

[6]. M. Moghavvemi, L. C. Seng, "PYROELECTRIC INFRRARED SENSOR FOR INTRUDERDETECTION", Proc. IEEE Region 10 Conf. (TENCON 2004), vol. 4, pp.656-659, 2004-Nov.

[7]. www.arduino.cc

[8]. https://www.tutorialspoint.com/internet_of_things/index.htm 